\title{
DYNAMISM INSIDE THE MO BOX: THE CREDIBILITY OF MARKET INFORMATION AS A KEY FACTOR IN MARKET ORIENTATION
}

\author{
Yuko Yamashita*, Wataru Uehara*, Gen Fukutomi**, \\ MASAto SASAKI ${ }^{*}$, AND HiroyUKi FuKUCHI ${ }^{* * *}$
}

\begin{abstract}
Our research contributes mainly to two fields: one concerns the influence of the marketing department, and the other is the study of market orientation, especially research that views market orientation as an information process. Motivated by discussion of marketing's declining influence within the company, we investigated the marketing department's credibility and influence in Japanese firms, where it has traditionally wielded weaker power than in Western firms. From intensive interviews with marketing professionals, we find that the lack of credibility of market information is a crucial factor that undercuts the influence of the marketing department. The results of our questionnaire survey indicate that the credibility of market information has a more positively significant effect on market orientation than does marketing influence.
\end{abstract}

Keywords: Market orientation, credibility of market information, marketing department's influence, marketing capability

Coinciding with the end of the Cold War, 1990 was a watershed year for research into market orientation. Motivated by the epochal papers published that year by Kohli and Jaworski and by Narver and Slater, researchers around the world have made enormous contributions, enriching the field (Kirca et al. 2005). Specifically, the drastic changes that moved the global economy toward market orientation may have been the background for the development of such large-scale interest in the subject.

Implicitly in the world of marketing, however, the primary factor behind this evolution would have been the growing recognition, shared by academic researchers as well as business practitioners, that marketing was experiencing a significant change, perhaps even facing a crisis of decline (Webster, Jr., Malter, and Ganesan 2005). Ironically, the more market-oriented firms became, the less significant the influence of marketing seems to have become. We observed the emergence of interest in researching the influence of marketing, propelled by the shared recognition of a marketing crisis. One stream of research connects the influence of the marketing department with contingent factors (Homburg, Workman, Jr., and Krohmer 1999).

\footnotetext{
* Hitotsubashi University

** Kyoto Sangyo University

*** Toyo Gakuen University
} 
Another stream treats the influence of the marketing department as related to its capabilities, and examines their antecedents, arguing that the marketing department is important, as it generates intelligence about the relationship between customers, products, and services. (Verhoef and Leeflang 2009; Moorman and Rust 1999).

Continuing research has reported that market orientation contributes to firms' performance. In addition to empirical studies in the US context, researchers have been reconfirming the contribution of market orientation globally, from Australia to Zimbabwe (Mavondo 1999), ranging methodologically from clinical studies to field research (Armstrong and Collopy 1996), constructing a rich literature of the field (Kirca et al. 2005). The purpose of this paper is to examine the raison d'être of the marketing department, which we expect to leverage an organization's market orientation. We focus on two variables as antecedents to market orientation: the credibility of market information and the influence of the marketing department. These variables may seem to be redundant, as the original articles by Kohli and Jaworski (1990), Kohi, Jaworski, and Kumar (1993), and Narver and Slater (1990) have indicated that top management emphasis, trust of the marketing manager by non-marketing managers, or interdepartmental conflict and coordination affect market orientation. Against this anxiety, we succeeded in shedding light on the black box of market orientation, which is constructed of various departments' thoughts and actions. Market orientation is a sequential process of its components (Homburg, Grozdanovic, and Klarmann 2007) that includes the causes and results of various activities. We reveal the dynamism of these components, i.e., intelligence generation, intelligence dissemination, and responsive actions. We also examine the impact on firm performance, in relation to the credibility and influence of the marketing department, based on the conceptual model, framed below.

\section{A Conceptual Framework}

There is no skepticism regarding the significance of market orientation in improving a firm's performance. Market orientation is a concept concerning the corporate organization as a whole; thus, earlier research treated the influence of the marketing department as an exogenous factor to marketing orientation. As seen above, in research about the antecedents of market orientation, factors including the top management or interdepartmental coordination are considered, but are not necessarily the results of the actions of the marketing department. The role of marketing seems to be obscured by setting market orientation as a scale to measure holistic, corporate-level marketing performance. If market orientation is a representation of the marketing philosophy in a corporate organization, how is marketing involved? This is our central question.

\section{Market Orientation and the Marketing Department}

In the rich history of research in the field of market orientation, there are two most distinguished perspectives: behavioral and cultural. The former refers to Kohli and Jaworski (1990) and the latter, to Narver and Slater (1990). Our study adopts the behavioral perspective, while we also appreciate the cultural perspective.

The cultural perspective focuses on the structural and rooted belief systems within 
organizations. If market orientation is deeply culture-bound, it would be difficult to transform. Since our interests lie in marketing's role, we do not assume a firm to be a monolithic, indivisible whole, but rather to be a structured composite of units, where marketing can play an essential role in encouraging the firm's market orientation.

By taking a cultural perspective, though, Harris (1999) implies the cultural dominance of the marketing department. Verhoef and Leeflang (2009) argue that a strong marketing department can induce a market-oriented culture. Top management can move organizational culture toward market orientation by supporting a capable, strong marketing department. The reasons behind the marketing department's dominance are noted by Gebhardt, Carpenter, and Sherry (2006), who point out the market-connecting role of a marketing department as a crucial source of market-oriented culture.

We take a behavioral perspective, while respecting the arguments set forth by cultural perspective advocates. We are inspired by their arguments in the following ways: (1) their focus on the role of the marketing department in the overall organization of the firm; (2) their focus on the function of marketing in market orientation; and (3) their focus on the lack of cohesiveness in behavioral perspective research. Nonetheless, we support a behavioral perspective for three reasons, as follow.

First, the firm can be market-oriented without having a strong marketing department as the center of its cultural belief system. We wish to explain this phenomenon, wherein marketoriented activities are promoted even in the absence of a strong marketing department.

Second, as regards the marketing function, assuming the promotion of market-orientation as the marketing department's key role would infer a strong methodological causality between market orientation and marketing's influence (Verhoef and Leeflang 2009). What, then, are the key activities of the marketing department? We assume that its crucial role is in strategic analysis and planning, not in the promotion of market orientation.

This is connected to our third point: cohesiveness. We share the argument from the cultural perspective that the behavioral perspective lacks the key conceptual/organizational center needed to unite a set of activities, but we do not identify culture as the sole cohesive force. Instead, we assert strategic marketing analysis to be the key function of the marketing department. Authors like Homburg, Grozdanovic, and Klarmann (2007) add the planning function to the behavioral framework. We are also motivated by the argument of Jarzabkowski and Balogun (2009), who stress strategic planning in delivering integration. In order to coordinate complicated, diverse, and often contentious marketing activities, people must share a view of the market, which is only arrived at through thoughtful analysis and judgment. This brings us to a focus on two variables: credibility of market information and the marketing department's influence.

\section{The Marketing Department and the Credibility of Market Information}

Based on the behavioral view, market orientation is a sequential process of intelligence generation and dissemination, followed by the actions of organizations in response. Rather than a black box that brings benefits for a certain organization, researchers have begun examining causal relationships of these components and firm performance (Homburg, Krohmer, and Workman, Jr. 2004; Homburg, Grozdanovic, and Klarmann 2007). Market orientation is an activity that goes beyond functional borders and departmental boundaries (Krohmer, Homburg, 
and Workman, Jr. 2002). The cultural view never neglects this, as it sets interfunctional coordination as a key construct of market orientation.

Therefore, the identification of the antecedents to interfunctional coordination and conflict is an important task for researchers like Maltz and Kohli (2000), as they are critical variables in developing a market-oriented organization. However, instead of measuring interfunctional coordination and its antecedents, we employ the credibility of market information and the marketing department's influence as factors which improve market orientation for the following two reasons.

First, let us reconsider that market orientation is a sequential process comprehending information collection, information dissemination, and organizational response. Especially the latter sequence of market orientation involves more actors from different departments, as an organization tries to harmonize various activities to converge on the final products, services, or any realization of the firm's strategy. When casting an eye on this sequence, interfunctional coordination may not exert its influence on these three components equally. Although we do not doubt its value as an antecedent to market orientation, we exclude interfunctional coordination from the independent variables. Instead, just as we are to focus on the causal relationship of the components, we direct our attention to the credibility of market information and the influence of the marketing department as components of interfunctional coordination.

Our second reason has its origins in our central question: How is the marketing department involved in improving market orientation? We consider market information to be a resource that the marketing department earns. Resource interdependency holds the key to interfunctional coordination (Ruekert and Walker, Jr. 1987). In the mechanisms of market orientation, information is usually collected and disseminated, not raw but in a processed form. Judgment and decisions are applied. Responses might sometimes stem from conditioned reflex without conscious consideration, but mostly show thoughtful reflection. The marketing department is deeply involved in this process as the entity in charge of analysis and planning (Homburg, Grozdanovic, and Klarmann 2007). When information is regarded as credible, organizations respond. We often confront situations where information is meticulously gathered but does not reach beyond the organizational walls. Or, information may be well-disseminated but is not taken seriously. We assume that information has the power to elicit response when perceived as credible. The source of the power of marketing is information (Atuahene-Gima and De Luca 2008); when marketing has knowledge sufficient, for example, to connect customers, products, and service delivery, a cooperative relationship with other departments is achieved (Moorman and Rust 1999). Other studies show that when marketing has expertise as its resource, market information is organizationally utilized. Empirical studies involving sales departments (Malshe 2009) and R\&D departments (Gupta and Wilemon 1988; Moenaert and Souder 1996; Song, Xie, and Di Benedetto 2001) have proven that market information crosses departmental borders to be exploited.

Hence, we see market information and intelligence as a resource that the marketing department accumulates. After intensive interviews with marketing professionals, we find that the lack of credibility of marketing information is a crucial factor that interferes with the influence of the marketing department. However well the information is developed, if it is not considered credible, that information is not taken seriously, and then not disseminated, yielding no response. The receiver of the information decides to take action only after he or she endorses its credibility (Goldsmith, et al. 2000). Market information is fully utilized when 
trusted by its receiver (Maltz and Kohli 1996); organizational resource utilization stems from trust or credibility between various actors (Fang, et al. 2008).

This factor of trust may be treated as a quality of the marketing department in existing research (Verhoef and Leeflang 2009), as it is perceived to be a consequence of marketing skills. However, we propose viewing credibility as the evaluation of market information, thereby fitting it into the information-processing perspective of a market orientation. Capabilities are more general concepts and have statistical impact on market orientation, but credibility is behaviorally bound to elements of market orientation. The reasons we propose to further research credibility are as follows.

First, credibility reflects the evaluation of information generated by the marketing department. In other words, actors from other departments evaluate whether or not market information is a dependable resource. Marketing capabilities are the judgment of people in the marketing department. Market information-the outcome of marketing department efforts-however, is exposed to organizational reality and is often judged according to the context experienced by the user of the information.

Second, credibility conceptually comes close to market orientation, as it is strongly connected to the information lifecycle. Moorman and Rust (1999) analyze the evaluation of the marketing department, and we focus on the information generated by the marketing department. Information processing often takes on a self-fulfilling character. The more that analysis by the marketing department is taken to be credible among organization members, the more cohesive the response to the information, and thus the more effective the chain of activities becomes.

Third, credibility results in higher profitability. Since marketing concerns the efforts to make unknown markets known, its processes are fundamentally accompanied by uncertainty. A reduction of uncertainty would result in higher profitability.

\section{The Marketing Department and its Influence}

In addition to the credibility of market information, we also see the marketing department's influence as a critical factor affecting chains of market-oriented activities. The influence of the marketing department has recently attracted increasing academic interest. There are three basic approaches to this research. The first approach explains influence in relation to contingent factors which surround the firm (Homburg, Workman, Jr., and Krohmer 1999). The second approach connects influence to organizational antecedents (Verhoef and Leeflang 2009). And, the third explains marketing influence as connected to marketing department capabilities (Vorhies, Morgan, and Autry 2009). Verhoef and Leeflang view marketing capabilities as consisting of accountability, innovation, customer connection, creativity, and integration/cooperation, among which accountability and innovation show the most significant impact. And when marketing plays an influential role in marketing activities, organizations become highly effective, efficient, and adaptive (Krohmer, Homburg, and Workman, Jr. 2002).

Across the whole scope of market orientation research, marketing influence is positioned as a direct antecedent to market orientation, whereby the other organizational antecedents including marketing capabilities affect market orientation via marketing influence. If this is the case, the contribution of influence research would be in offering factors very closely linked to market orientation.

This is important if we consider the difficulties business practitioners face, given their 
firms' market orientation scores. Influence, which consists of factors like the perceived importance of the marketing department, respect in the boardroom, and decision influence (Verhoef and Leeflang 2009), offers managers managerial and/or organizational devices to improve the market orientation of their firms. Given top management support, the marketing department can achieve influential dominance, and thereby contribute to higher market orientation (Kirca, Jayachandran, and Bearden 2005).

The influence of the marketing department can be independent of whether its practices are credible among other departments. As we question the role of marketing, we are better able to argue if marketing can be influential in improving and smoothing market-oriented activities. Utilization of market intelligence is a function of credibility and influence that the marketing department achieves, and these variables are originally conceptualized by Maltz and Kohli (1996) as trust and power, respectively. Thus, we include two key variables in our conceptual model: (1) credibility, which refers to how the receiver treats market information, defined as trust in the information generated by the marketing department (or functional marketing subunit); and (2) influence, referring to how its sender can exercise power. Some argue that the influential roles of different departments are indispensable in achieving better performance (Atuahene-Gima and Evangelista 2000). With these two key variables to harness market orientation, we make thorough use of different perspectives on the role of marketing: (1) that credibility represents a resource-based perspective; (2) that influence represents a sociopolitical perspective; and (3) the view of market orientation as seen from an information-processing perspective. These three perspectives are identified by Li and Atuahene-Gima (1999). We do not intend to use these variables as opposites; rather, we attempt to explain their cause-effect relationships.

Based on a literature review and findings from our interviews with marketing professionals, we extracted a conceptual model, illustrated in Figure 1. In the following section, we review our hypotheses.

\section{Hypotheses}

What is behind the difference between firms in which the three stages of market orientation are smoothly connected and firms where they are hampered? Considering the voluminous research accumulated in this field, we can point out many antecedents that affect market orientation. Here, we propose examining the credibility of market information in order to better understand the direct role of marketing in the composition of market orientation.

\section{Credibility of Market Information and Market Orientation}

The credibility of market information is the main variable of our focus. We propose this variable to supplement the information-processing view of market orientation (Kohli and Jaworski 1990; Jaworski and Kohli 1993).

H1: The greater the credibility of market information becomes, the more market-oriented a business unit becomes.

This hypothesis consists of three sub-components as we pay attention to qualitative differences 
among the three major components of Kohli and Jaworski's classification of market orientation. That is,

H1a: The greater the credibility of market information, the higher the level of intelligence generation activity in a business unit.

H1b: The greater the credibility of market information, the higher the level of intelligence dissemination activity in a business unit.

H1c: The greater the credibility of market information, the more responsive a business unit becomes.

\section{The Marketing Department's Influence on Market Orientation}

Even if the marketing department succeeds in developing valuable information, it cannot contribute to the organization without becoming influential. Verhoef and Leeflang (2009) found that a strong, dominant marketing department could be seen as a driving force of market orientation. Their argument is motivated by Moorman and Rust (1999) who claimed that studies praising market orientation tended to ignore the specific activities of the marketing department.

To reexamine the idea that the existence of an influential marketing department improves market orientation, we hypothesize:

$\mathrm{H} 2$ : The stronger the influence of the marketing department becomes, the more marketoriented a business unit becomes.

This consists of the following elements:

H2a: The stronger the influence of a marketing department, the higher the level of intelligence generation activity in a business unit.

$\mathrm{H} 2 \mathrm{~b}$ : The stronger the influence of a marketing department, the higher the level of intelligence dissemination activity in a business unit.

H2c: The stronger the influence of a marketing department, the more responsive a business unit becomes.

\section{Dynamism in the Black Box of Market Orientation and its Impact on Business Performance}

As mentioned in the previous section, we follow past literature that treats market orientation as a sequence (Homburg, Krohmer, and Workman, Jr. 2004; Homburg, Grozdanovic, and Klarmann 2007). Kohli and Jaworski's (1990) original concept of market orientation consists of three sub-concepts: market intelligence generation, intelligence dissemination, and responsiveness. We assume that these concepts are not parallel activities, but occur as a series of information-processing activities. Firms gather market and customer data, and spread them to related departments. Then, marketing and other departments consider and implement various measures to improve their current situation. If these activities can be assumed to be a series of processes, there would be a causal relationship among these three activities. This assumption was already borne out by Japanese firm data by the authors; the current study also fundamentally adheres to a causal relationship of market-oriented activities. Thus, we hypothesize: 
H3: Market orientation is a series of information-processing activities.

This means:

H3a: A higher level of intelligence generation activity animates intelligence dissemination in a business unit.

H3b: A higher level of intelligence dissemination activity animates a business unit to be more responsive.

As the findings of accumulated studies have outlined, market orientation has a positive impact on business performance in various environments.

H4: Market orientation has a positive impact on the perceived performance of a business unit.

Intelligence generation is not supposed to affect business performance without organizational exploitation of intelligence. Intelligence dissemination may make an organization innovative or proactive in gaining profits, as well as bless an organization with the chance to be responsive to customers and competitors. Thus, $\mathrm{H} 4$ consists of elements as follows:

H4a: A higher level of intelligence dissemination activity brings better performance to a business unit.

H4b: The more responsive a business unit becomes, the better performance it achieves.

\section{Method}

The objectives of this research are twofold. First, we intend to clarify how market orientation is affected by the credibility of market information and the marketing department's influence. Second, we wish to reach a deeper understanding of the interplay of these concepts with market orientation. We also examine the effects of those factors on firm performance.

Toward these objectives, we engaged in empirical research on large-scale Japanese firms in various industries. Before conducting a questionnaire survey, we held in-depth interviews with top management, marketing managers, and marketing professionals, such as consultants, researchers and academic scholars, to identify factors which hinder market orientation in the Japanese business environment. An extensive questionnaire survey of Japanese firms was then conducted, in which we collected data on market orientation, the credibility of marketing information, the influence of marketing units within a firm, and the firm's performance.

\section{Data Collection}

Our data consists of responses regarding a range of unit and organizational functions measuring market orientation in different areas and positions. In each business unit, three basic functions ( $R \& D$, production, and sales and marketing) and three levels of seniority (head of a business unit, middle manager, and lower-level manager) were selected. Questionnaires were sent to the selected respondents from January through March 2009 via a staff manager in the corporate personnel or planning department. 1,021 managers in 139 business units, representing 20 Japanese firms, responded. These companies operate in consumer and business markets, 
offering both services and goods (including durables and nondurables). We excluded all respondents who did not complete the entire survey, leaving a sample of 999 respondents, comprising sales and marketing managers (37.7\%), production managers (17.9\%), R\&D managers $(16.2 \%)$, and managers in other departments.

\section{Measurement}

Credibility of market information. Scales were created to measure the degree to which information from the marketing department is trusted by other departments. For marketing managers, these scales represent their conscience and sense of fairness in their daily activities. To measure the credibility of market information, we cited John and Martin (1984), who examined the relationship between types of organizational structures and marketing plan utilization, as well as its credibility, as dependent variables. Rather than the organizational structures or the content of marketing plans, we directed our focus to the role of the marketing department especially in intelligence generation and dissemination to encourage organizational response. Thus, we employed two scales of information: (1) specificity, and (2) consistency, from their six elements of credibility. We added another set of scales to employ four scales for credibility.

Source credibility is also crucial as it attracts many researchers in advertising studies or broad applied psychology literature where information is considered to enforce action on the receivers or to draw desirable consequences from them (Ohanian 1990). Because market information is expected to reinforce organizational activities among others, we employ two scales measuring source credibility. To be concrete, these are scales asking (3) whether the source is specific, and (4) whether the purpose or intention of information collection is explicit (Monenaert and Souder 1990, 1996; Song, Xie, and Di Benedetto 2001). Under the assumption that marketing is in charge of intelligence generation, we examine the significance of the marketing department as an important source of information.

To finish our explanation of measures of credibility, we would like to mention the reason we use the term credibility, rather than trust, which may confuse the argument as the two terms have many conceptual characteristics in common. We define the term trust as the result of certain activities by certain actors. On the contrary, we intend to measure credibility as the result and means of the marketing department through which it gains trust from other departments. That is why we investigate whether the source of information and the purpose of its collection are specific and traceable.

The marketing department's influence. The influence of the marketing department is measured directly through the respondents' impressions.

Market orientation. A market orientation scale was designed, based on the Kohli, Jaworski, and Kumar (1993) scale called MARKOR. As market orientation is considered difficult for managers to observe in their competitors, we used a standard Likert seven-point scale.

Business performance. We assessed business performance by asking respondents for their subjective assessments of their business units. Because the business performance of major competitors is observable, we used seven-point scales with "much worse than competitors" and "much better than competitors" anchors (Morgan, Vorhies, and Mason 2009). See the Appendix 
for the specific item indicators and questions used in our research.

\section{Results of Hypotheses Testing}

Descriptive statistics for the collected data are presented in Table 1. We test our hypotheses by using structural equation modeling (SEM). Our model, which is shown in Figure 2 , is judged to fit well with the data $\left(\chi^{2}=440.68, p=0.00\right.$, GFI $=0.96$, AGFI $=0.95$, CFI $=0.96$, RMSEA $=0.037$ ). The results of our SEM analysis are presented in Table $2 . \mathrm{We}$ used latent variables to measure each concept other than the marketing department's influence. Scale items consisting of each concept are also cited in Table 1. To note, the results and our statements will not be different when we average scores of our scale items.

The results show that the credibility of market information has a positive significant effect on three activities related to market orientation, which suggests strong support of hypotheses $\mathrm{H} 1 \mathrm{a}, \mathrm{H} 1 \mathrm{~b}$, and H1c. But Table 2 shows that the influence of the marketing department has a limited effect on market orientation. It does not have a significant effect on intelligence generation and dissemination. $\mathrm{H} 2 \mathrm{a}$ and $\mathrm{H} 2 \mathrm{~b}$ are not supported, while $\mathrm{H} 2 \mathrm{c}$ is partially supported. The results show that the credibility of market information has a stronger positive effect on market orientation. The total effects on business performance, as described in Table 3, also suggest the importance of credibility. Market orientation, on the whole, guides a business unit to better performance, whereas intelligence generation activity itself does not. $\mathrm{H} 4 \mathrm{~b}$ and $\mathrm{H} 4 \mathrm{c}$ are supported, while $\mathrm{H} 4 \mathrm{a}$ is not.

\section{Conclusion and Discussion}

Our research contributes mainly to two areas. One is study of the influence of the marketing department (Homburg, et al. 1999; Moorman and Rust 1999; Verhoef and Leeflang 2009) and another is market orientation research, of which research that views market orientation as a set of processes is the most relevant.

Motivated by discussion of marketing's declining influence within the firm (Webster, Jr., Malter, and Ganesan 2005), we investigated the role of marketing credibility and influence. Our results indicate that the credibility of market information has a more positively significant effect on market orientation than does marketing influence. Influence of the marketing department is only effective to draw responsive actions from the organization, to a remarkably small extent.

Our research also shows clearly that three individual processes of market orientation, i.e. intelligence generation, intelligence dissemination, and responsiveness, are independently structured. Importantly, each process has a different impact on business performance: the latter two processes, dissemination and responsiveness, have impact on business performance. This suggests that information generation alone is not a sufficient condition for business performance. When intelligence generation is combined with dissemination and responsiveness, it is more likely to succeed.

Now, we discuss two topics on (1) the relative impact of the credibility of market information compared with the marketing department's influence, and (2) the relationship between credibility and intelligence generation. Following this discussion, implications and 
limitations are introduced.

\section{Credibility of Market Information and the Marketing Department's Influence}

As shown in our results of hypotheses $\mathrm{H} 1$ and $\mathrm{H} 2$ testing, the influence of the marketing department has less impact on market orientation than does credibility. This may happen when R\&D, manufacturing, or other departments practice market-oriented activities without the involvement of the marketing department, especially when those other departments actively engage in intelligence generation and dissemination. Conflict occurs between departments when one is delegated power without the ability to appropriately exercise it on the others (French and Raven 1959; Cartwright and Zander, 1968).

Otherwise, we must note that there is a non-linear relationship between the marketing department's influence and market orientation. As reviewed above, the marketing department can be influential in leveraging market orientation (Verhoef and Leeflang 2009), while the influence of marketing departments appears to be weaker when market orientation scores higher at the overall organizational level (Day 1992). Here, of course, the specificity of Japanese business practices like cross-functional decision-making may be a reason.

Cultural settings can never be ignored. A dominant marketing department could be seen as a driving force for market orientation (Verhoef and Leeflang 2009); this is true at least in most US domestic contexts. But this might not be the case in a different business environment. Our empirical research on Japanese firms provides a case from one such environment, where the power of the marketing department is considered to be weaker than that of their Western counterparts. It is argued that the marketing department is very strong in the US, while relatively weak in Germany and Japan (Homburg, Workman, Jr., and Krohmer 1999). Japanese firms generally are, however, not at all market-disoriented. Different organizational settings seem to enable marketing influence, even in the absence of a dominant marketing department. This aligns with the argument of authors such as McKenna (1991) and Webster, Malter, and Ganesan (2005) concerning the diffusion of the marketing concept. These scholars argue that the role of marketing as a driver for the diffusion of the marketing concept is becoming less significant. In many Japanese firms, marketing does not necessarily require an independent department. Instead, a marketing subunit exists in the product unit, sales department, or management staff division. There, differences in the role of marketing are even more pronounced than in cases where there are independent central marketing departments. Each business has its own way of achieving market orientation for which people work together. In such an environment, accountability would be too heavy a burden for marketing to bear. International comparison is required for further argument on this topic.

\section{Credibility of Market Information and Intelligence Generation Activity}

Concerning hypotheses $\mathrm{H} 3 \mathrm{a}$ through $\mathrm{H} 3 \mathrm{c}$, we observed that the credibility of market information has its most powerful impact on intelligence generation rather than on dissemination or responsiveness. As we cannot deny the possibility that intelligence generation activity increases credibility, we have conducted an ex-post analysis to examine the path in the reverse direction, as shown in Figure 3. We kept other variables and paths unchanged.

Our ex-post analysis model showed a good fit with the data $\left(\chi^{2}=440.68, p=0.00\right.$, 
$\mathrm{GFI}=0.96, \mathrm{AGFI}=0.94, \mathrm{CFI}=0.96, \mathrm{RMSEA}=0.037$ ), almost indistinguishable from the model tested previously. The path from intelligence generation to credibility is significant (the standardized coefficient is .54) and still shows a strong interrelation between the two variables. Overall structure and all other significant path coefficients are in the same direction as in the previous model, except that the path from influence to intelligence generation appears as a positive one.

\section{Implications}

Market orientation involves different actors from various organizational levels. This is why we have to observe the causal relationships of its components, instead of leaving it in a black box. We reexamined the idea that market orientation is an interdepartmental concept, consisting of the heterogeneous thoughts and actions of various functions.

The credibility of market information is an important antecedent to market orientation. This variable interrelates with intelligence generation, and the influence of the marketing department has different impacts on the three components of market orientation. Therefore, so as to examine the antecedents of market orientation, we have to suppose that any antecedent has its effect on the components independently. There seem to be pitfalls when we try to find factors to boost market orientation as a whole.

This argument has practical relevance as well. Structural empowerment of the marketing department is less significant than the improvement of intelligence generation or dissemination activities per se. Although top management emphasis on market orientation is very important, executives or managers should never forget about improvement or remediation in each sequential activity. Such remedial efforts must be harmonized with the top management emphasis.

With regard to the scales applied in this study, we measured credibility in terms of trust as its result, as well as a means to acquire trust from others. No one claims that it is easy to generate credible information. But our results imply that one may succeed in disseminating information to other departments, when he or she specifies the purpose of information generation and identifies those in charge of this activity.

\section{Limitations and Directions for Future Research}

We foresee some research to overcome the limitations of this study. Japanese sample bias and the lack of an external validity check are major limitations. International and comparative studies are required.

Our ongoing research is on how to improve credibility, especially on how technical and professional activities of the marketing department contribute to gaining trust from other departments. Marketing plan credibility stems from the marketing department's analytical techniques, market analyses, and plan components (Piercy and Morgan 1994). To enrich this field of research, we now turn our focus toward strategic marketing activities such as segmentation, targeting, positioning, and allocation of the marketing mix. These strategic activities are the stage at which the marketing department can demonstrate its expertise to gain credibility. This research assignment may provide us with insight into the problem of dispersion and the decline of marketing. 


\section{REFERENCES}

Armstrong, J. Scott, and Fred Collopy. 1996. "Competitor Orientation: Effects of Objectives and Information on Managerial Decisions and Profitability." Journal of Marketing Research 33:188-199.

Atuahene-Gima, Kwaku and Luigi M. De Luca. 2008. "Marketing's Lateral Influence Strategies and New Product Team Comprehension in High-Tech Companies: A Cross-National Investigation." Industrial Marketing Management. 37(6) August: 664676.

Atuahene-Gima, Kwaku and Felicitas Evangelista. 2000. "Cross-Functional Influence in New Product Development: An Exploratory Study of Marketing and R\&D Perspectives." Management Science. 46 (10): 1269-1284.

Cartwright, Dorwin and Alvin F. Zander. Eds. (1968) Group Dynamics: Research and Theory. 3rd Ed. New York: Harper and Row.

Day, George S. (1992). Marketing's Contribution to the Strategy Dialogue. Journal of the Academy of Marketing Science. 20 (4): 323-329.

Day, George S. (1994). The capability of market-driven organizations. Journal of Marketing, 58 (October): 37-52.

Deshpandé, R., \& Farley, J. U. (1999). Understanding market orientation: A prospectively designed meta-analysis of three market orientation scales. In Developing a Market Orientation, ed. Rohit Deshpandé, 217-36. California: Sage.

Dobni, B. C., \& Luffman, G. (2000). Implementing marketing strategy through market orientation. Journal of Marketing Management, 16 (November): 895-916.

Fang, Eric, Robert W. Palmatier, Lisa K. Scheer, and Ning Li. (2008). Trust at Different Organizational Levels. Journal of Marketing. 72 (March): 80-98.

French, J. R. P., Raven, B. (1959). The Bases of Social Power. in Cartwright, Dorwin and Alvin F. Zander, Eds., Group Dynamics. New York: Harper \& Row.

Gebhardt, G. F., Carpenter, G. S., \& Sherry, J. F. (2006). Creating a market orientation: A longitudinal, multi-firm, grounded analysis of cultural transformation. Journal of Marketing, 70 (October): 37-55.

Goldsmith, Robert E., Barbara A. Lafferty and Stephen J. Newell. (2000) The Impact of Corporate Credibility and Celebrity Credibility on Consumer Reaction to Advertisements and Brands. Journal of Advertising. 29(3): 43-54.

Gupta, Ashok K. and David Wilemon. (1988). The Credibility-Cooperation Connection at the R\&D-Marketing Interface. Journal of Product Innovation Management, 5(1): 20-31.

Harris, L. C. (1999). Developing a market-oriented culture: A critical evaluation. Journal of Management Studies, 36 (2): 179-96.

Homburg, C., Grozdanovic, M., \& Klarmann, M. (2007). Responsiveness to customers and competitors: The role of affective and cognitive organizational systems. Journal of Marketing, 71 (July): 18-38.

Homburg, Christian, Harley Krohmer and John P. Workman, Jr. (2004). A Strategy Implementation Perspective of Market Orientation. Journal of Business Research. 57(12): 1331-1340.

Homburg, C., Workman, J. P. Jr., \& Krohmer, H. (1999). Marketing's influence within the firm. Journal of Marketing, 63 (April): 1-17. 
Hult, G. T. M., Ketchen, D. J. Jr., \& Slater, S. F. ( 2005). Market Orientation and Performance: An Integration of Disparate Approaches. Strategic Management Journal, 26 (December): 1173-81.

Jarzabkowski, P., \& Balogun, J. (2009). The practice and process of delivering integration through strategic planning. Journal of Management Studies, 46 (December): 1255-88.

Jaworski, B. J., \& Kohli, A. K. (1993). Market orientation: Antecedents and consequences. Journal of Marketing, 57 (July): 53-70.

John, George and John Martin. (1984). Effects of Organizational Structure of Marketing Planning on Credibility and Utilization of Plan Output. Journal of Marketing Research. 21 (2): 170-183.

Kirca, A. H., Jayachandran, A., \& Bearden, W. O. ( 2005). Market orientation: A metaanalytic review and assessment of its antecedents and impact on performance. Journal of Marketing, 69 (April): 24-41.

Kohli, A. K., \& Jaworski, B. J.(1990). Market orientation: The construct, research propositions, and managerial implications. Journal of Marketing, 54 (April): 1-18.

Kohli, A. K., Jaworski, B. J., \& Kumar, A. (1993). MARKOR: A measure of market orientation. Journal of Marketing Research, 30 (November): 467-77.

Krohmer, Harley, Christian Homburg, and John P. Workman, Jr. (2002). Should Marketing Be Cross-Functional? Conceptual Development and International Empirical Evidence. Journal of Business Research. 55 (6): 451-465.

Li, Haiyang, and Kwaku Atuahene-Gima. (1999). Marketing's Influence and New Product Performance in Chinese Firms. Journal of International Marketing. 7 (1): 34-56.

Malshe, Avinash. (2010). How Is Marketer's Credibility Construed Within the Sales-Marketing Interface? Journal of Business Research. 63 (1): 13-19.

Maltz, Elliot and Ajay Kohli. (1996). Market Intelligence Dissemination Across Functional Boundaries. Journal of Marketing Research. 33 (1): 47-61.

Maltz, Elliot and Ajay Kohli. (2000). Reducing Marketing's Conflict With Other Functions: The Differential Effects of Integrating Mechanisms. Journal of the Academy of Marketing Science. 28 (4): 479-492.

Mavondo, D. Felix Tinoziva. 1999. "Market Orientation: Scale Invariance and Relationship to Generic Strategies Across Two Countries." Journal of Market-Focused Management 4: 125-142.

McKenna, R. (1991). Marketing is everything. Harvard Business Review, 69 (JanuaryFebruary): 65-79.

Moenaert, Rudy K. and William E. Souder. (1990) An Information Transfer Model for Integrating Marketing and R\&D Personnel in New Product Development Projects. Journal of Product Innovation Management. 7 (2): 91-107.

Moenaert, Rudy K. and William E. Souder. (1996) Context and Antecedents of Information Utility at the R\&D/Marketing Interface. Management Science. 42 (11): 1592-1610.

Moorman, C., \& Rust, R. T. (1999). The role of marketing. Journal of Marketing, 63 (October): 180-97.

Morgan, Neil A. and Nigel F. Piercy. (1998). Interactions Between Marketing and Quality at the SBU Level: Influences and Outcomes. Journal of the Academy of Marketing Science. 26 (3): 190-208.

Morgan, N. A., Vorhies, D. W., \& Mason, C. M. (2009). Market orientation, marketing 
capabilities, and firm performance. Strategic Management Journal, 30 (August): 909-20.

Narver, J. C., \& Stanley F. S. (1990). The effect of a market orientation on business profitability. Journal of Marketing, 54 (October): 20-35.

Ohanian, Roobina. (1990). Construction and Validation of a Scale to Measure Celebrity Endorsers' Perceived Expertise, Trustworthiness, and Attractiveness. Journal of Advertising. 19 (3): 39-52.

Piercy, Nigel F. and Neil A. Morgan. (1994). The Marketing Planning Process: Behavioral Problems Compared to Analytical Techniques in Explaining Marketing Plan Credibility. Journal of Business Research. 29(3): 167-178.

Ruekert, Robert W., and Orville C. Walker, Jr. 1987, 'Marketing's Interaction with Other Functional Units: A Conceptual Framework and Empirical Evidence,' in Journal of Marketing. Vol. 51. January. pp. 1-19.

Slater, S. F., \& Narver, J. C. (1994). Does competitive environment moderate the market orientation-performance relationship? Journal of Marketing, 58 (January): 46-55.

Song, Michael, Jinhong Xie, and C. Anthony Di Benedetto. (2001). Message and Source Factors, Market Uncertainty, and Extrafunctional Information Processing: Hypotheses and Empirical Evidence. IEEE Transactions on Engineering Management. 48 (2): 223-238.

Verhoef, Peter C., \& Peter S. H. Leeflang. 2009. Understanding the marketing department's influence within the firm. Journal of Marketing, 73 (March): 14-37.

Vorhies, D. W. (1998). An investigation of the factors leading to the development of marketing capabilities and organizational effectiveness. Journal of Strategic Marketing, 6 (1): 3-23.

Vorhies, D. W., Morgan, R. E. \& Autry, C. W. (2009). Product-market strategy and the marketing capabilities of the firm: Impact on market effectiveness and cash flow performance. Strategic Management Review, 30 (December): 1310-34.

Webster, F. E. Jr., Malter A. J., \& Ganesan, S. (2005). The decline and dispersion of marketing competence. Sloan Management Review, 46 (Summer): 35-43. 